\title{
INFLUENCIA EDUCATIVA DE LOS MEDIOS DE COMUNICACIÓN SOCIAL EN LA SOCIEDAD NEOLIBERAL
}

\author{
Educational influences of the mass-media \\ in the neoliberal society
}

Julio VERA VILA

Universidad de Málaga. Facultad de Ciencias de la Educación. Departamento de Teoría e Historia de la Educación. Campus de Teatinos. 29071 Málaga.

juliovera@uma.es

Fecha de aceptación definitiva: marzo de 2002

BIBLID [(1130-3743) 13, 2001, 187-208]

\section{RESUMEN}

Este trabajo es una reflexión acerca de la forma en la que se articulan y operan los medios de comunicación en lo que se ha dado en llamar el neoliberalismo y cuál es, en ese contexto, su influencia educativa. Los medios de comunicación entendidos como conjunto de empresas que tienen por misión informar a las personas de lo que ocurre en el mundo, han jugado y juegan un importante papel social. Desde el punto de vista educativo, el análisis del mundo de la comunicación en el contexto neoliberal actual, invita a demandar mayores dosis de educación ciudadana. Ser ciudadanos autónomos y críticos en unos entornos persuasivos tan poderosos, con tal cantidad de información, exige potenciar los procesos educativos y una distribución más igualitaria de los recursos y dispositivos formativos disponibles.

Palabras clave: medios de comunicación, educación mediática. 
SUMMARY

This work is a reflection about the form in which the media are articulated and the way they operate in the neoliberalism and which is, in that context, its educational influence. The media understood as a group of companies that have for mission to inform people of what happens in the world, has played and they play an important social role. From the educational point of view, the analysis of the world of the communication in the neoliberal context, invites to demand more civic education. To be autonomous and critical citizens in such persuasive environments, with so many information, it demands to foster the educational processes and a more equitable distribution of the available formative resources.

Key words: mass-media, mediatical education.

\section{INTRODUCCIÓN}

Los medios de comunicación son, en gran parte, los responsables de la imagen de la realidad que tienen los ciudadanos, de sus actitudes, de sus valores y de sus acciones. No son omnipotentes, pero sí muy influyentes. Influyen en los individuos, en las organizaciones, en las capas dirigentes, en las esferas intelectuales. Tradicionalmente han sido considerados como uno de los pilares fundamentales de la democracia por su capacidad para conformar los estados de opinión pública, por su papel de mediación entre los dirigentes y los ciudadanos, por su pluralismo informativo, por su capacidad de control político, etc. Pero lo que nos interesa en este tema es su influencia educativa. Desde una perspectiva pedagógica, la educación conforma un sistema de dispositivos, instituciones, programas, etc., que deben servir para el desarrollo individual y el bienestar social, por eso, para que esas instituciones puedan cumplir mejor sus funciones es necesario analizar los factores que potencian y los que inhiben, en un momento determinado, los procesos educativos. Las preguntas serían, por lo tanto, las siguientes: ¿Qué tipo de influencias educativas ejercen los medios de comunicación en la fase actual del neoliberalismo? ¿Contribuyen al desarrollo individual y al bienestar social? ¿Potencian o inhiben un modelo de desarrollo compatible con los derechos humanos y el ideal de democracia? ¿Acrecientan, limitan o condicionan el sentido crítico propio de una ciudadanía activa? ¿Son plurales e independientes cuando informan, o están al servicio de grupos que no representan los intereses mayoritarios?

Por otra parte, hay otros dos aspectos que están estrechamente relacionados con los medios de comunicación y el neoliberalismo: el papel de la publicidad en la sociedad de consumo y el debilitamiento de la democracia cuando se convierte en simple marketing político. 


\section{Liberalismo Político, globalización de la ECONOMÍA Y DESARROLlO HUMANO}

A la hora de analizar el liberalismo podemos distinguir dos facetas: la política y la económica. En la esfera de lo político el liberalismo ha hecho contribuciones importantes al desarrollo moral del hombre que merecen ser preservadas, desarrolladas y mejoradas. Fueron las ideas liberales las que inspiraron, desde la Revolución francesa, los derechos humanos de la primera generación, es decir, los civiles y políticos. Entre ellos, la libertad de conciencia, la libertad de expresión, la de asociación, la de reunión, el derecho a la participación política a través del voto y el acceso a la representación política, y también, por supuesto, el derecho a la propiedad privada. Fueron ideas liberales las que primero impulsaron el pacto social que se expresa en las constituciones, con expresión de los derechos y deberes ciudadanos, y luego, defendieron la separación de los poderes legislativo, ejecutivo y judicial como garantía de independencia y control mutuo. En su vertiente política, por lo tanto, hay en el liberalismo ideas positivas que han contribuido al bienestar social y que con su lógica evolución han contribuido a conformar la realidad actual, logrando un consenso bastante grande en torno a ellas.

Es, en cambio, en los aspectos económicos donde el liberalismo ha sido más duramente criticado y el predominio de lo uno sobre lo otro es determinante, porque es el liberalismo económico actual, es decir, el neoliberalismo, uno de los mayores enemigos de los principios políticos mencionados anteriormente, cuyas raíces son también liberales. Para decirlo de otra manera, el neoliberalismo es hoy un obstáculo importante para la profundización de la democracia política.

Tras la caída del muro de Berlín y el proceso de reforma política iniciado en la maltrecha Unión Soviética, comienza a hablarse del neoliberalismo como ideología y forma de vida que aspira a imponerse a escala mundial. Sus características más sobresalientes son las siguientes: globalización de la economía, libertad de circulación de capitales, desaparición de las barreras proteccionistas en el comercio, flexibilización del mercado de trabajo, es decir, control salarial y disminución de la carga impositiva de las empresas; legitimación del liberalismo sin fronteras como ideología o pensamiento único, gestión de las economías menos desarrolladas a través de las ayudas condicionadas de los organismos económicos internacionales; y finalmente, como resultado de lo anterior, el predominio del beneficio económico inmediato, sobre los objetivos ético-políticos y el desarrollo de los derechos humanos.

El costo de este modelo de desarrollo, centrado en el beneficio económico a través de la libre competencia entre agentes abismalmente desiguales, está siendo enorme. La globalización económica significa que las grandes empresas que operan en todo el mundo llegan a acaparar un poder suficiente como para condicionar las decisiones políticas de los gobiernos de muchos países. Así, las 15 mayores empresas tienen un ingreso bruto mayor que 120 países y las 500 mayores multinacionales generan el 25\% de PIB mundial, pero sólo ocupan al 1,25\% de la población activa global (Arnanz y Ardid, 1996, 76-77). La cultura del consumismo 
sostenida por la publicidad, la moda y la potente industria mediática de los países occidentales, aparece como el modelo ideal de felicidad y bienestar social, cuando la realidad demuestra la explotación a la que están sometidos los trabajadores de los países subdesarrollados, incluidos los niños, donde el 20\% de la población mundial acaba disfrutando del $80 \%$ de la riqueza mundial.

Como indica Colom $(1998,31)$, hay que diferenciar los conceptos de crecimiento y desarrollo. Crecimiento significa elementos tales como mayor acumulación de capital y mayor disponibilidad económica, pero por sí solos, no se traducen en desarrollo. Éste, en cambio, se refiere a la capacidad para atender los derechos básicos de los ciudadanos: sanidad, educación, vivienda, empleo, cultura, etc. De hecho, ni siquiera los países desarrollados se salvan de los desequilibrios entre un gran crecimiento y un desarrollo desigualmente repartido, como evidencian las grandes bolsas de pobreza de las grandes ciudades.

En definitiva, la globalización de la economía y el crecimiento económico no ha tenido, ni tiene, un marco de controles democráticos suficientemente fuertes, como para orientar sus beneficios al servicio del desarrollo de la comunidad humana. Ese marco necesario, cuyos cimientos ya existen, debiera ser un sistema jurídico internacional de protección de los derechos humanos. Sin éstos, la idea de democracia queda reducida a un conjunto de resortes formales para elegir a los gobernantes. Como indiqué al comienzo de este epígrafe, la propia evolución del liberalismo económico es, hoy por hoy, un freno para el desarrollo no sólo de los derechos sociales, económicos y culturales, que impulsó el socialismo, sino de las propias libertades fundamentales cuya raíz fue liberal.

Los medios de comunicación, como empresas que son, están sometidos a los mismos procesos de globalización, concentración empresarial, competitividad, publicidad de sus productos, etc. Pero su función social y la enorme influencia que ejercen sobre la sociedad, aumentan la trascendencia de las transformaciones que están sufriendo.

3. Las transformaciones en el mundo de la información. NuEvos Retos educativos

\subsection{La sobreproducción de información}

Las nuevas tecnologías, su interrelación, los avances del conocimiento y las posibilidades de difundir más mensajes en menos tiempo han dado lugar a una sobreproducción de información, que está siendo explotada comercialmente como cualquier otro bien de consumo. Publicitar toda esa mercancía es hoy una necesidad imperiosa para generar una demanda de dimensiones equivalentes a la capacidad de producción. El público por lo tanto va a sufrir la presión de los mecanismos de persuasión publicitaria para consumir cada vez mayores cantidades de información. Como desgraciadamente la cantidad no es siempre garantía de calidad, las personas, si no quieren sucumbir a esta sobreabundancia indiscriminada, necesitarán una buena formación que les permita fijar criterios claros para orientar sus vidas 
y, en función de ellos, discriminar aquellas informaciones que les van a ayudar de las que sólo les van a distraer.

Los sucesivos medios de comunicación que han ido apareciendo a lo largo de la historia de la humanidad no han hecho sino aumentar la cantidad de información disponible, diversificar los medios de transporte de la misma y acelerar la rapidez con la que circula. A lo largo de ese recorrido histórico el hombre y las sociedades han dispuesto de períodos cada vez más cortos para adaptarse a todos esos cambios. En el momento actual, la información se produce en tales cantidades, por medios tan diversos y a una velocidad tan grande, que el problema es cómo seleccionarla, asimilarla y controlarla al servicio de objetivos valiosos al mismo ritmo en que se produce. "Por poner un ejemplo, cada día, alrededor de 20 millones de palabras de información técnica se imprimen en diversos soportes (revistas, libros, informes, disquetes, CD-Rom). Un lector capaz de leer 1.000 palabras por minuto, ocho horas cada día, emplearía un mes y medio en leer la producción de una sola jornada, y al final de ese tiempo habría acumulado un retraso de cinco años y medio de lectura..." (Ramonet, 1998, 218). El modelo humanista del saber se ha convertido en un proyecto imposible. Ni se puede saber todo, ni seguramente es conveniente, pero determinar qué aprendizajes merece la pena adquirir a lo largo de la vida es uno de los dilemas pedagógicos más difíciles de resolver. Pero ése ya no es un problema de desarrollo tecnológico, sino humano y social, aunque la respuesta sea también de vital interés para las empresas.

Quizás ahora que hemos tomado clara conciencia de estar desbordados por la información, valoremos más los procesos de construcción personal, lo que somos capaces de hacer e imaginar con las ideas que cada uno tenemos independientemente de su cantidad. Tal vez decidamos trabajar más conjuntamente para complementar nuestras competencias individuales y pedirnos sólo el desarrollo que queramos para los demás. Si no podemos conocer todo lo que es valioso, fiable y creíble; si aun conociéndolo cada uno ha de tener el derecho de elegir su ideal de felicidad, aprendamos al menos a discernir y desechar lo banal, lo injusto, lo falso, aquello que es contrario a la dignidad humana y nadie lo querría para sí mismo.

Postman en su estimulante obra titulada Tecnópolis $(1994,88)$, advierte que la información es peligrosa "cuando no tiene ningún sitio al que dirigirse, cuando no hay teoría a la que aplicarla, ningún modelo en el que encaje, cuando no hay propósito al que sirva". Y es que si la falta de información es un problema, su exceso no lo es menos. La información no es un fin en sí misma, ni tampoco las nuevas tecnologías que operan con ella. Ambas sólo son instrumentos necesarios, pero instrumentos al servicio de proyectos humanos que diseñan, gestionan y evalúan las personas. Ése ha sido y sigue siendo el problema humano por antonomasia, el de encontrar el sentido que dé valor a la vida humana en la doble perspectiva individual y colectiva.

Desde el punto de vista educativo, el análisis del mundo de la comunicación en el contexto neoliberal actual, invita a demandar mayores dosis de educación ciudadana. Ser ciudadanos autónomos y críticos en unos entornos persuasivos tan 
poderosos, con tal cantidad de información, exige una potenciación de los procesos educativos y una distribución más igualitaria de los recursos y dispositivos formativos disponibles.

\subsection{Las grandes concentraciones de empresas multimedia y las desigualdades en materia de información}

La globalización del mercado de la comunicación está produciendo grandes concentraciones entre las empresas de telefonía, informática, televisión, publicidad, prensa, radio, cine, etc. La idea es poder ofrecer un conjunto de servicios en el ámbito mundial, aprovechando las posibilidades tecnológicas de la integración de todos esos medios, a fin de competir por espacios más amplios del mercado mundial.

Integración de tecnologías que se complementan y se potencias unas a otras; empresas que se fusionan para acometer inversiones a escala mundial y servicios relacionados con la comunicación y la información cada vez más amplios, son algunas de características del mundo de la información en lo que se ha dado en llamar el neoliberalismo.

Como las pequeñas empresas no pueden cubrir todos los frentes de lo que sucede en el mundo entero, tienen que abastecerse en el mercado de noticias, donde unas cuantas agencias venden sus imágenes: Visnews (británica), WTN (anglo-norteamericana), CBS (norteamericana), y CNN (norteamericana). Las fusiones entre empresas que producen, controlan y distribuyen un material tan sensible como es la información, suponen un peligro real para la profundización de la democracia política, para la libertad de información, para el derecho a estar bien informado y la participación plural en la toma de decisiones. Cuando el poder de informar se concentra en muy pocas manos y alcanza a todos los rincones del planeta, es necesario prevenirse ante la tentación de usar ese poder contra los intereses de la mayoría.

El desequilibrio en materia de información en favor de los países desarrollados, fundamentalmente Estados Unidos, Japón y la Unión Europea, es tan grande que representa una seria amenaza para la diversidad cultural de los menos desarrollados. Ellos controlan el $90 \%$ de la producción de bienes y servicios de información mundiales y el $80 \%$ de las fusiones se producen entre empresas de esas tres áreas. Según datos de la Unesco de 1990, de las 300 empresas más importantes de información y comunicación, el 48\% eran norteamericanas, el 27\% de la Unión Europea, el 16\% japonesas y el 9\% restante de otros países desarrollados (Canadá, Australia, Suiza, etc.). Cifras parecidas se repiten en el mundo de la prensa escrita, de las empresas de informática y de las que fabrican material de comunicación. De la cifra global de negocio que representaba en 1990 la economía de la información (1 billón 185 mil millones de dólares), el 42\% lo generaba Estados Unidos, algo más del 21\% la Unión Europea y un poco menos Japón. El resto lo generaron empresas del resto del mundo, casi todas ellas del Norte. Algunos expertos prevén que, 
en unos pocos años, en el sector de la informática y las telecomunicaciones 7 u 8 redes de empresas multinacionales se repartirán dos tercios del mercado mundial (Ramonet, 1998, 149-150). Un dominio tan grande de los mensajes de los que se nutre la mayor parte de la población mundial, significa que sobre cualquier asunto conflictivo o banal que se presente, va a predominar el punto de vista más cercano a los intereses occidentales. El dominio de las empresas de comunicación, aparte de suponer una de las mayores fuentes de ingresos por exportación, supone la difusión de los valores culturales, sobre todo de los Estados Unidos, a escala planetaria.

La unión del teléfono, el ordenador y la televisión hace posible integrar texto, sonido e imágenes animadas para formar hipertextos o realidad virtual. A través de esos medios interactivos, esas redes empresariales podrán ofrecer servicios relativos a todas las esferas de la vida humana: entretenimiento, publicidad, información, cursos de formación, foros, relaciones interpersonales, transacciones económicas, gestiones administrativas, toma de decisiones, etc. Podremos vivir digitalizados utilizando la información como una materia prima inagotable. Las limitaciones económicas serán un regulador de las infinitas posibilidades de elección dentro de esa nueva vida virtual. El otro regulador fundamental debería ser una educación sólida capaz de orientarnos con criterios éticos y sociales. El problema es que así como ya es accesible la digitalización de la información, no se pueden digitalizar los procesos cognitivos, afectivos ni actitudinales. Seleccionar la información, comprenderla y saber utilizarla requiere tiempo y práctica. Este fenómeno caracterizado por la diferencia entre la velocidad a la que se producen los cambios y el tiempo que tardamos en desarrollar capacidades para asimilarlos se conoce con el nombre de desfase bumano.

Todas las enormes posibilidades que ofrecen las tecnologías de la información están mediatizadas por su desigual distribución, por ello, la idea liberal de dejar campo libre a la competencia entre individuos libres en un mercado libre significa legitimar y ahondar aún más las diferencias que ya existen en materia de información. En 1995, el número de ordenadores personales en uso en el mundo era de 180 millones para una población de 6.000 millones de habitantes, es decir, que sólo el 3\% tenía posibilidad de acceder a la red. El 15\% de la población mundial poseía las 3/4 partes de las líneas telefónicas, sin las cuales no se puede acceder a Internet (Schiller, 1998, 73-75). En marzo de 1993 la revista Byte estimaba que de los 30 millones de usuarios del correo electrónico, sólo unos millares eran de América Latina y unos cientos de África (Bissio, 1998, 126).

A menudo se alude al abaratamiento de los equipos informáticos para demostrar que cada día son más accesibles, pero también es igualmente cierto que el envejecimiento acelerado, tanto de los equipos como de los programas, obligan a una renovación permanente que no está al alcance de todos. Pero aun disponiendo de medios excelentes para todos, seguiría existiendo un foso entre quienes poseen los conocimientos necesarios para navegar con provecho por entre las aguas del océano de informaciones y quienes ni siquiera saben leer ni escribir. No es sólo un problema de simplicidad de manejo de la técnica, ni de alfabetización informática, 
es un auténtico problema de desfase humano debido a la divergencia entre la rapidez de los cambios tecnológicos y la lentitud del desarrollo humano y comunitario.

Por otra parte, no toda la información es gratuita. Las empresas van a seguir vendiendo sus servicios o sufragándolos con publicidad. Y cada sesión de publicidad comercial es una inmersión real en los valores que sustentan el sistema. Las técnicas variarán y se adaptarán a las posibilidades interactivas y lúdicas que ofrecen los nuevos soportes, pero la finalidad será la misma. En definitiva, el mundo de la información forma parte de la realidad y está sometido a los mismos condicionantes. Si es verdad que los medios de comunicación son extensiones del hombre, su radio de alcance será proporcional a las diferencias que separan a unos de otros. No se trata de criticar a los medios de comunicación, sino de reclamar que se pongan al servicio de políticas de bienestar individual y social.

\subsection{La globalización: un mercado sin fronteras}

El predominio de los intereses financieros sobre la planificación política entendida como la gestión del bien común o de los intereses generales, unido a las posibilidades de las nuevas tecnologías, ha hecho que las barreras comerciales vayan desapareciendo o debilitándose. El comercio se está liberalizando en el ámbito mundial, incluso antes de que existan mecanismos de control que lo puedan racionalizar. Los grandes capitales pueden en cuestión de horas sostener o debilitar las economías reales de sectores enteros y con ello los programas políticos que las impulsan.

La libre circulación de la información en un mercado globalizado supone, pues, el predominio de los mejor situados que concentran en pocas manos el control de los medios de comunicación: informática, telefonía y mass-media. Es verdad que nunca antes hemos podido disponer de tanta información, pero tampoco, nunca antes, unos pocos han controlado tantos medios ni tanta información sobre los más variados asuntos: política, economía, educación, juegos, cultura, entretenimiento... ¿Están estos medios en condiciones de defender los intereses de los ciudadanos cuando entren en colisión con los de las empresas, los anunciantes, o los accionistas? ¿Puede sobrevivir una prensa independiente y a la vez sobrevivir a la competencia sin banalizar sus contenidos? ¿Puede la prensa ser crítica con el poder sin ejercer presiones en favor de sus intereses comerciales? Es muy difícil contestar afirmativamente.

\subsection{La tecnología como ideología}

Actualmente asistimos a un deslumbramiento de las tecnologías de la información que nos lleva al convencimiento de que pueden ser el remedio mágico de todos los males. Cuando dejamos de verlas como instrumentos limitados, con sus ventajas y sus inconvenientes, y empezamos a creer que pueden ser, por sí mismas 
y sin más, el remedio definitivo a todos las grandes problemas que preocupan al hombre, las estamos colocando en el lugar que no les corresponde y pidiéndoles soluciones que no están capacitadas para darnos. La deificación de la tecnología la convierte en una ideología en torno a la cual se articulan los demás elementos fundamentales de la cultura, dando lugar a un discurso nuevo en el que se han cambiado los significados que permiten a las personas situarse y comprenderse en la realidad.

Postman (1994) analiza las diferentes formas de cultura según el uso que hacen de las tecnologías. En primer lugar están, según este autor, las culturas que utilizan herramientas que permiten resolver problemas concretos, pero que no introducen cambios significativos en su visión del mundo. En segundo lugar se sitúan las tecnocracias que son aquellas culturas que a partir del siglo XVII, gracias a la revolución industrial, el auge de la ciencia y las posibilidades tecnológicas de controlar la naturaleza, comienzan a confiar en que la gestión eficaz de los medios conducirá al progreso generalizado. La tecnocracia subvierte el orden de los factores dentro de la cultura, de manera que la técnica, lo instrumental, se impone a los demás elementos que la dotan de dirección y sentido: la religión, la política, las ideologías, el arte, etc. En último lugar, se encuentra Tecnópolis, nombre que designa aquel tipo de cultura en el que la idea del progreso humano ha sido sustituida por la del progreso tecnológico, debido a la creencia de que son los avances instrumentales los que permiten gestionar eficazmente los recursos escasos, es decir, la economía. Objetivos económicos y desarrollos tecnológicos se han convertido en los dos elementos hegemónicos dentro de la cultura.

No creo que nadie esté en disposición de negar el gran avance que representan las innovaciones tecnológicas ni la importancia de la economía. Ésa no es la cuestión. Lo verdaderamente peligroso es que sean esas dos esferas las que marquen los objetivos y la dirección de la cultura. Pensar que la tecnología es el nuevo gran relato que nos promete un mundo mejor es convertir el "medio en el mensaje». La tecnología no es un mensaje, es un medio. Sólo cuando lo divinizamos y le conferimos el poder que no tiene, se convierte en el nuevo mensaje, en el nuevo relato, es decir, en una ideología. Nuestros problemas más graves como la pobreza, la violencia, el analfabetismo, no son problemas técnicos ni surgen por falta de información. La tecnología puede hacer tanto por remediarlos como por empeorarlos, todo depende de la dirección en la que se oriente y esa dirección debe ser discutida a través de unos cauces de representación democrática. Sin embargo, la orientación de la política va en la dirección contraria, es decir, retirando los mecanismos de contrapeso que pueden limitar y racionalizar el enorme poder que acumulan las empresas privadas, incluidas las relacionadas con la información.

Una nota característica de la orientación que está tomando el cambio social actual es el aumento de los lenguajes, su sincretismo, la tendencia a codificar la realidad con nuevas claves y con lenguajes que incorporan las ventajas y las limitaciones de los anteriores. En ese sentido, las nuevas tecnologías vienen a incrementar el número de experiencias cifradas, es decir, simuladas, artificiales. A 
medida que la innovación tecnológica avanza nos encontramos con socieclades capaces de ofrecer más realidades sucedáneas, virtuales, artificiales, elaboradas, y ello nos dota de unas enormes posibilidades para lo bueno y para lo malo. Toffler, que es un autor que sabe revestir sus brillantes ideas con el lenguaje más persuasivo, dice que «llegaremos a ser la primera cultura de la Historia que empleará la más avanzada tecnología para fabricar el producto más transitorio y, sin embargo, más duradero, la experiencia humana" $(1976,292)$. Esas nuevas formas, cada vez más logradas, de representación simbólica ofrecen muchas oportunidades para ensayar papeles o estilos de vida sin necesidad de sufrir las consecuencias desagradables que tales experiencias podrían acarrear en la vida real. Pero a la vez, en la medida en que las imágenes dejen de representar la realidad contribuirán a deformar el modelo mental del mundo por el que las personas rigen su conducta. En este sentido, nos enfrentamos a dos problemas: a) adquirir un aprendizaje muy rápido para incorporar/desechar conocimientos, formas alternativas de tratar los datos y nuevos modos de pensar y valorar $y, b)$ aprender a vivir en un mundo en el que la realidad simulada cuenta más para saber vivir en la realidad real. Progresivamente nuestras imágenes de la realidad son más fugaces, las obtenemos más de nuestra experiencia simbólica y ésta se hace más extensiva aunque pierde en intensidad.

Nunca antes hemos tenido tanta urgencia, ni tantas posibilidades para educar, pero la educación seguirá compitiendo con otras industrias alienantes de experiencias simuladas. Si para vivir en una cultura estática se necesitan niveles elementales de aprendizaje, en las culturas altamente tecnificadas, la educación permanente es indispensable, porque la misma realidad a la que debemos adaptarnos está cada vez más sometida a procesos de transformación artificial.

La definición de los fines y la determinación de los criterios para la evaluación pedagógica de los entornos de aprendizaje se convierten en la cuestión fundamental en la medida en que los medios, con ser instrumentos muy eficaces, carecen en sí mismos de orientación. En una sociedad en cambio acelerado y con herramientas tan poderosas son prioritarios los fines y la participación democrática en su formulación. Por ello, el problema está mal planteado si lo formulamos como "tecnologías sí o tecnologías no". El problema es resolver a qué objetivos se destinan prioritariamente y con qué uso.

La variable tecnológica, con ser sumamente importante, debe jugar, en los procesos de innovación, el papel de una variable dependiente que se supedita a la orientación global del cambio. Por lo tanto, ha de haber una serie de criterios que sirvan para valorar la pertinencia o no de las tecnologías y de su uso, en relación con su contribución a la orientación global del mismo (Vera, 1997). Debe ser la orientación innovadora la que determine el papel de las nuevas tecnologías y no al revés, ya que de lo contrario se podrían perpetuar modelos educativos obsoletos e ineficaces aun cuando introdujeran en su dinámica el uso de las tecnologías más avanzadas (Escudero, 1995). 


\subsection{El predominio de la información como poder}

¿Qué queremos decir realmente cuando decimos que la información es poder? Evidentemente estar informado sobre algo permite actuar con conocimiento de causa, evita tener que recurrir en exceso al aprendizaje por ensayo y error, evita pérdidas innecesarias de tiempo y permite tomar decisiones más lúcidas. Por lo tanto, la información es necesaria para comportarnos racionalmente. Por ello, quien controla siquiera una parte de la información, está en disposición de mediatizar la toma de decisiones de los que no la tienen. Eso es lo que está pasando con las empresas de la comunicación y de la información. Quien controla, administra, elabora o distribuye la información sobre algo, gestiona el mundo de los significados y la imagen de la realidad.

Los medios de comunicación, en la teoría clásica del poder eran considerados como el cuarto poder y se pensaba que una de sus misiones fundamentales era la de controlar a los demás poderes: político, legislativo y judicial. Sin embargo, este juego de contrapoderes está cambiando sustancialmente poniendo en riesgo los mecanismos tradicionales de representación política que se han venido desarrollando desde la Grecia clásica y la Revolución francesa, al menos en el mundo occidental. Los intereses económicos de las grandes empresas que operan en el marco de la libertad de comercio mundial, y dentro de ellas, las de la comunicación, tienen capacidad para condicionar las decisiones de quienes han sido elegidos democráticamente. Pueden en cuestión de días deteriorar o edulcorar la imagen de cualquier político. Pueden crear un estado de opinión pública favorable o desfavorable a un programa electoral, de igual modo y con la misma rapidez con la que pueden crear un estado de necesidad consumista en los ciudadanos (Vera, 1998).

Por su parte, el ciudadano se encuentra con una sobreabundancia de información, que se renueva a un ritmo vertiginoso y que le exige niveles de formación, criterios selectivos y conocimientos respecto a las fuentes que no posee. Si añadimos que, como veremos, la información gratuita, la que dispensan los medios masivos como la televisión, está caracterizada por la espectacularidad, el sensacionalismo y podríamos añadir la banalidad, la superficialidad o la diversión, el panorama desde el punto de vista educativo no es muy alentador.

\subsection{La simplificación de la información e impacto emocional}

Una de las características de la información actual es el aumento del componente emocional en detrimento del racional. Es un cambio en el modelo persuasivo que ya no pretende tanto convencer con argumentos mejores o peores, como producir una hiperestimulación sensorial y emocional. Antes la prensa sensacionalista era un sector especializado, dirigido a un pequeño sector del público, que no gozaba del aprecio ni de las personas más cultivadas, ni de los profesionales del ramo, ni de buena parte del público. Era una especialidad desacreditada y en minoría. En cambio, desde hace unos años, todos los medios de comunicación serios 
fueron introduciendo secciones dedicadas a lo que era exclusivo de la llamada prensa del corazón y, poco a poco, fueron dándole un tratamiento más espectacular y sensacionalista a su programación, de manera que se ha ido convirtiendo en una mezcla de entretenimiento, diversión, espectáculo, sensacionalismo y prensa del corazón. Las buenas películas y los programas más serios de análisis y debate han quedado relegados a los márgenes horarios de primeras horas de la mañana o las últimas de la noche.

El análisis argumental típico de la racionalidad está siendo desplazado por paquetes de estímulos elaborados con el objetivo de excitar los sentidos y desbordar sentimentalmente a los receptores. Espectáculo y emotividad forman parte de los ingredientes con los que se construyen la mayor parte de los programas de las televisiones y demás medios de comunicación. El mundo de la información periodística está sufriendo grandes mutaciones. La información ya no trata de producir conocimiento relevante sobre algunos hechos, que era a lo que tradicionalmente hemos llamado estar informado. Ahora prima el estilo de la televisión, que ocupa el primer lugar en la jerarquía de los medios y cuyas características son las siguientes (Ramonet, 1998): presentar el acontecimiento en directo, convertir la imagen en el elemento fundamental de la noticia, priorizar el espectáculo, confundir la veracidad con la imagen o con el número de medios que se hacen eco de una noticia, anteponer la inmediatez a la reflexión, etc.

\section{LA PUBLICIDAD Y LA SOCIEDAD DE CONSUMO}

En el momento actual, y desde la mitad del siglo xx, el centro de gravedad de la economía mundial se ha desplazado desde la producción al consumo. Y esto ha ocurrido porque producir bienes ha dejado de ser un problema; el problema es ahora distribuir todo lo que se produce. La dificultad no está en la producción sino en la venta.

Hasta la llegada de la civilización industrial, es decir, antes del siglo xvIII, no existía diferenciación entre producción y consumo, pero durante la primera mitad del pasado siglo, sobre todo a raíz de la Primera Guerra Mundial, se despertó un deseo de elevar el nivel de vida, lo que unido a la necesidad de reconstruir lo destruido, produjo una gran demanda de los más variados productos. Para satisfacer esa demanda se realizó la llamada segunda revolución industrial, con sus métodos de producción en serie, la racionalización del trabajo, los automatismos, etc. La dificultad entonces era, fundamentalmente, producir, no vender. Es lo que Toffler (1981: 53) denomina la segunda ola.

La sociedad de consumo se consolida desde el momento en que para que la producción no se detenga, es decir, para que haya crecimiento económico, se hace necesario invertir en consumo, en la creación y mantenimiento de comportamientos consumistas (Cueto, 1981, 10-11). A partir de ese momento, junto a los mecanismos de producción, se van a desarrollar otros de control e incentivo de los 
comportamientos de consumo, como si fueran otra mercancía más: la publicidad, el marketing, los nuevos sistemas de distribución y venta, los sondeos de mercado, las técnicas de motivación, etc.

La vigencia social de los significados añadidos a los objetos de consumo depende de dos sistemas: la publicidad y la moda. La publicidad difunde un mensaje previamente elaborado por un equipo de expertos, cuyo objetivo es el de persuadir al consumidor de que el producto ostenta simbólicamente unas cualidades y unos valores que son deseables. Previamente ha sido calculado el grado de reiteración necesario para hacer vigente ese valor. La moda, por su parte, cumple otra importante función: la de convertir los significados vigentes en transitorios. De esta forma, la moda publicitada condiciona la comunicación, al cambiar periódicamente la carga semántica (el significado) de las cosas, mientras que la reiteración constante la legitima como fuente prescriptora de valores de usar y tirar, aquí y ahora. Por paradójico que parezca, la moda se absolutiza como referente permanente relativizando todo lo demás, cuya vigencia tiene un alto grado de caducidad.

La publicidad es un fenómeno que o bien facilita y promueve la sociabilidad a través de aprendizajes valiosos a lo largo del proceso de socialización, o bien los inhibe y los dificulta. Aparentemente, su objetivo se limita a persuadir del uso y consumo de productos, servicios o instituciones; sin embargo contribuye, en el marco de la sociedad de consumo, a instaurar valores y modelos de vida. Su aparente trivialidad hace que sus efectos no comerciales, y más concretamente los socioeducativos, pasen desapercibidos, pero basta un simple análisis de sus contenidos para darse cuenta de que en los anuncios comerciales se dan cita contenidos axiológicos, ideológicos, educativos, psicológicos, etc., tratados a través de todos los lenguajes (sonidos, palabras, imágenes, grafismos, etc.) y condensados en mensajes cortos, seductores y divertidos.

Dentro de ese contexto podemos considerarla como un agente de socialización secundaria, con unos métodos y unos efectos determinados, que interactúa con los demás agentes socializadores. Para comprender mejor su papel hay que situarla en el contexto de la sociedad de consumo, un modelo de sociedad basado en el predominio de lo material, lo económico, el individualismo y los valores de usar y tirar. En su funcionamiento son fundamentales dos hechos íntimamente relacionados (Vera, 1995): el descrédito de las ideologías del esfuerzo y el apogeo de las doctrinas de la libertad individual. Un concepto de libertad más sesgado hacia la desculpabilización, el hedonismo y la tolerancia egoísta que hacia la solidaridad. Pues bien, los mensajes comerciales son en la actualidad los auténticos portavoces del sistema social actual, mucho más que los agentes de socialización tradicionales.

Desde el punto de vista de la educación interesa estudiar especialmente el papel de la publicidad como un agente más de integración y exclusión social. Esta función podemos analizarla desde tres puntos de vista: a) la capacidad adquisitiva de los sujetos como condición para entrar y mantenerse en la dinámica del consumismo; una dinámica que afecta a todas las clases sociales, pero especialmente a las que han de hacer un mayor esfuerzo económico en proporción a sus ingresos; 
b) la presión que ejerce la moda sobre quienes se resisten a la tendencia de la mayoría, especialmente los jóvenes, los sujetos con menor autoestima y los que tienen más difícil destacar en otras facetas; y c) el valor simbólico que la publicidad incorpora a los productos, cargándolos de significados sociales como el prestigio social, la belleza, la modernidad, el poder, el atractivo físico, etc. Estos tres factores interrelacionados refuerzan el papel de control social de la publicidad/moda por medio de esos sutiles mecanismos de integración, estratificación y exclusión social, lo cual no es sino una fuente de frustración e insatisfacción para amplias capas de la población de todas las edades.

Un primer nivel de intervención para contrarrestar sus efectos negativos es el de la regulación legal de la publicidad, en el que es posible incidir descle las asociaciones de consumidores y desde aquellas otras dedicadas a la integración de la mujer, de las minorías étnicas, de la infancia, etc. En este aspecto hay que reconocer la dificultad de hacer cumplir la normativa que protege los derechos de los consumidores reconocidos por la Constitución, debido a las sutilezas que emplea la publicidad, a sus múltiples formas y estrategias y a la entrada en juego de la publicidad implícita.

El otro aspecto es el de la consideración de la publicidad como un contenido a incluir en los diseños curriculares, no sólo en la escuela, sino también en las instituciones educativas del ámbito social. En esta tarea han de colaborar las diversas instituciones y ámbitos de intervención, teniendo en cuenta que los efectos educativos son mayores cuando hay congruencia de esfuerzos entre todos los agentes educativos por diferentes que éstos sean.

\section{EL MARKETING POLÍTICO Y EL EMPOBRECIMIENTO DE LA DEMOCRACIA}

Samir Amin $(1999,19)$ afirma que «la expansión del mercado moderno de los medios de comunicación constituye ya uno de los principales componentes de la erosión de las prácticas democráticas en el propio Occidente». Lamentablemente, los hechos parecen darle la razón.

La influencia del marketing en la política actual es evidente. Para tener éxito, un candidato debe pensar en sí mismo como si fuera un producto nuevo, capaz de satisfacer las expectativas de su población objetivo y teniendo en cuenta la competencia. Del mismo modo las ideologías son tratadas como embalajes y adornos que sirven para vender el candidato a un público que paga con votos. La misma aceptación universal de la publicidad y su ubicuidad han obligado a los políticos a entrar en los mismos moldes para acceder al público. Las consecuencias han sido, en su conjunto, desafortunadas, porque al igual que los publicitarios, los propagandistas políticos procuran evitar por todos los medios cualquier evaluación racional o crítica de sus planteamientos, mientras presentan una imagen deformada de sus adversarios (Qualter, 1994, 178). 
El uso de las técnicas de persuasión que intentan burlar el sentido crítico de los ciudadanos, o que presentan una imagen torcida de la realidad, o que provocan confusión, o que pretenden contrarrestar el efecto de otras noticias, puede afectar derechos tan fundamentales como la libertad ideológica, la libertad de expresión e información o la participación política. La mercantilización de los idearios políticos, convertidos en imágenes simplificadas, cuando no deformadas, a través de los medios de comunicación, afecta al ejercicio de los derechos personales, políticos y sociales que consagra nuestra Constitución (Díaz, 1995). Por ello, los medios de comunicación, los publicistas, las empresas, y los políticos, son también responsables de buena parte de los procesos informativos, formativos y recreativos en los que están inmersos los ciudadanos; es decir, son copartícipes de la responsabilidad educativa de toda la sociedad.

Suelen fijarse los orígenes de las democracias liberales en la Ilustración, en la Revolución francesa y en la Declaración Universal de los Derechos Humanos. Desde la declaración hasta aquí, ha transcurrido medio siglo. En ese corto período de tiempo, no sería justo decir que las democracias no han avanzado, aunque reconozcamos que tienen todavía que hacerlo más. Pero para ello es imprescindible la crítica activa de los ciudadanos. Debemos preguntarnos qué cambios permitirían profundizarlas y qué otros nos llevarían a desviarnos hacia posturas elitistas, oligárquicas o populistas (Rubio, 1996, 198).

Las democracias, como cualquier otra institución de progreso, atraviesan en su discurrir por diferentes períodos. Los críticos del sistema hablan, para manifestar su insatisfacción, de democracias formales, democracias burguesas y de democracias de masas, como tres amaneramientos de los ideales democráticos, cuya nota común es la de haber ralentizado el desarrollo de los derechos humanos. En esas tres formas incompletas de democracia se ha abusado de los recursos persuasivos de la propaganda política y del control de los medios de comunicación:

a) Las democracias son meramente formales, cuando los ciudadanos $y / 0$ las instituciones funcionan orgánicamente por inercia, imperando más el peso coercitivo de la ley que la convicción moral que la impulsa y promueve. Los déficits de la democracia se ponen también de manifiesto cuando se limita a la partitocracia: votar en las elecciones, competir por ganarlas, pactar bajo la presión de los más fuertes, etc.

b) Se habla de democracias burguesas cuando el desarrollo económico ha promovido a la gran mayoría a un nivel de bienestar general que posibilita que se instale en la defensa de sus derechos individuales y se debilite su solidaridad con las personas y los pueblos marginados.

c) Por último, el término democracia de masas alude a aquellas situaciones en las que la moral ciudadana se confunde con un individualismo tolerante que respeta la diferencia, más como un mecanismo de defensa de su privacidad, que como una forma de garantizar la participación de todos sin exclusiones. Alude también a las 
democracias que identifican el bienestar con el consumismo, la participación con el voto en las urnas, el liderazgo político con las habilidades comunicativas, los programas sociales con el marketing político, la comunidad con la masa, la motivación con el entretenimiento, la autorrealización con el hedonismo.

Si la democracia no hace avanzar la cultura de la participación en los modos de pensar, sentir y actuar, corre el riesgo de quedar reducida a una democracia espectadora y pasiva, gobernada por unas minorías que controlan los estados de opinión.

La educación no arregla todos los problemas de la democracia, pero en tanto apueste por una ciudadanía activa, crítica y solidaria se hará necesaria para que haya un compromiso personal y social, ya que por el momento, todavía nadie ha descubierto un instinto democrático que lo promueva por ella. La democracia es una finalidad y la forma de alcanzarla en un proceso histórico abierto a los avances y a los retrocesos.

La defensa moral de la democracia corresponde a todos los ciudadanos, y, por lo tanto, es toda la sociedad la responsable de educar. Ahora bien, desde el punto de vista profesional, los agentes encargados de hacer esta educación son los profesores y los educadores sociales, en las escuelas, en los servicios sociales y también a través de los medios de comunicación. La LOGSE permite un tratamiento escolar de todas estas cuestiones al considerar la educación moral y cívica como uno de los ejes transversales que ha de constituir el interés prioritario de todos los profesores cualquiera que sea el área o la materia en la que trabajen.

\section{De la globalización eCONÓMICA a la UNIVERSALIZACIÓN DE LOS DERECHOS HUMANOS}

El momento presente es una de esas etapas históricas en las que prevalece la complejidad sobre la simplicidad, el cambio sobre la permanencia y la diversidad sobre la uniformidad, lo que engendra un grado mayor o menor de desfase humano, concepto con el que se quiere expresar la distancia que media entre la creciente complejidad de la realidad y el retraso en el desarrollo de nuestras capacidades para hacerle frente (Botkin, Elmandjra y Malitza, 1979, 28). En este sentido, el crecimiento vertiginoso de los medios de comunicación y de todas las nuevas tecnologías de la información no se ha visto compensado con un incremento paralelo de las capacidades codificadoras, organizativas o de gestión que habilitan a las personas para su empleo consciente, por lo que éste es uno de los ámbitos culturales cuyo auge está generando mayor desfase humano entre la población. Hay también, en este terreno, un desfase social y una desigualdad de acceso a las fuentes de información, que en el futuro próximo amenaza con agrandar todavía más las diferencias (Mattelart, 1998).

Los medios de comunicación social y las nuevas tecnologías han de ser siempre bienvenidas como herramientas poderosas al servicio de la codificación, elaboración, gestión e intercambio de experiencias humanas, por lo que desde un punto de vista pedagógico interesa demandar su generalización como dispositivos 
útiles y eficaces de educación. Pero una vez subrayada su importancia como hardware susceptible de aplicación en múltiples modelos educativos, tanto en la escuela como fuera de ella, debemos también concentrarnos en el impacto configurador que realmente están teniendo, especialmente la televisión y el sistema publicidad/moda, en la población general como consecuencia del desfase existente entre su enorme potencial tecnológico y la pobreza cultural no sólo de sus mensajes sino del uso que se les da. Véase si no la instantaneidad con la que las viejas y nuevas tecnologías son aplicadas al ocio ensimismante y la demora con la que son empleadas con fines educativos.

Los medios de comunicación son, desde esta perspectiva, los dispositivos configuradores más potentes en la tarea de creación, difusión y refuerzo de unos modelos culturales de tipo simbólico en abierta contradicción con los modelos y valores promovidos por la institución escolar así como con su estilo transmisor. Ahora bien, la toma de conciencia del entorno cultural en el que circulan modelos y mensajes culturales contradictorios, ha de servir para promover la alfabetización audiovisual. El desfase humano creado por el crecimiento del poder persuasor de los medios no puede ser compensado pidiendo una utópica desaparición o censura de los mismos, sino reivindicando y desarrollando las tecnologías del crecimiento personal, es decir, revalorizando dentro del sistema estimativo público y privado el valor del aprendizaje educativo.

Hemos visto los riesgos que conlleva la concentración, en pocas manos, de las empresas que producen, gestionan y distribuyen la información. Esa concentración es el resultado lógico del predominio de la lógica capitalista que obliga a competir para optimizar los resultados. También hemos visto cómo el crecimiento no conduce automáticamente al desarrollo (Colom, 1998; Caride y Meira, 1998). Por ello, creo que es necesario, como sostiene Samir Amin $(1999,19)$ un nuevo proyecto humanista y alternativo de globalización que, basado en el principio de dignidad humana, pueda plantearse los problemas sociales a escala mundial. Lo cual es perfectamente compatible con la diversidad cultural y la cooperación entre instituciones de ámbito internacional, nacional o local.

Los derechos civiles y políticos encarnan el ideal de libertad. Son libertades que implican la no-injerencia autoritaria del poder en nuestras vidas: libertad de expresión, de conciencia, de desplazamiento, de asociación, de participación. Los derechos económicos, sociales y culturales encarnan el ideal de cooperación solidaria: derecho al trabajo, a la vivienda, a la salud, a la educación, etc. Estos derechos exigen el esfuerzo de todos y la intervención del Estado para garantizar a todos unos mínimos que hagan posible el acceso a las libertades. En un Estado democrático todos gozamos de libertad, pero unos ciudadanos pueden disfrutarla más que otros porque cuentan con los medios materiales para hacerlo. Quien carece de alimento, trabajo, educación, vivienda, etc., es libre, pero saca poco partido de serlo.

La universalización de los derechos humanos, lo que Cortina (1997) denomina la globalización ética, exige que el concepto actual de ciudadanía social sea 
entendido como el derecho a tener ambos tipos de derechos: el derecho a ser libre y el derecho a ejercer la libertad (derechos civiles y políticos más los derechos económicos, sociales y culturales). En eso consiste el Estado social de derecho. Hasta ahora ha sido ese modelo el que ha intentado dar cobijo al proyecto de ciudadanía social. Adela Cortina (1995) también usa el término Estado social de justicia, para que no se cargue a la cuenta del bienestar lo que es una elemental cuestión de justicia. Es un tipo de Estado que ha de estar basado en un pacto social para la defensa de la dignidad humana. El reto es universalizarlo.

\section{Algunas PROPUESTAS EDUCATIVAS}

El análisis de los efectos configuradores de los medios de comunicación en la lógica neoliberal nos exige reconocer su enorme influencia, con sus luces y sus sombras, y extraer algunas propuestas educativas:

a) Una primera propuesta sería la de aprender a manejar la gran cantidad de información indiscriminada de la que disponemos. La sobreabundancia de información actual junto a la reducción de los ciclos temporales de su renovación, exige la adquisición de nuevos aprendizajes que no eran tan necesarios en otras épocas históricas. Entre esos aprendizajes se encuentra la habilidad para seleccionar, filtrar, ordenar, valorar y asimilar la información de manera que se convierta en conocimiento manejable cotidianamente. Hay que tener en cuenta que la información no es conocimiento. Éste implica la organización personal de la información mediante la relación de unos conceptos con otros, lo que nos permite interpretar y explicar la realidad otorgándole significado. Por tanto, la misión de la escuela no es, sin más, transmitir el conocimiento considerando que ya está hecho y terminado, sino crearlo y construirlo permanentemente e insertarlo en una comunidad de significados (Rodríguez Neira, 2000, 19).

Como consecuencia de esa sobreabundancia de información, es de esperar que los contenidos escolares cambien el sentido que tradicionalmente han ocupado en relación con el desarrollo de las capacidades para trabajar con ellos. Es seguro que nunca podremos transmitir toda la información disponible, lo que sí podemos es ayudar a las personas a adquirir la formación y las actitudes necesarias para aprender a lo largo de su vida.

b) En segundo lugar, en una época caracterizada por la utilización de las más sofisticadas técnicas publicitarias y propagandísticas al servicio de intereses comerciales o ideológicos, se hace necesario educar para vivir en entornos persuasivos. El uso de técnicas de persuasión que intentan burlar el sentido crítico de los ciudadanos, o que presentan una imagen torcida de la realidad, o que provocan confusión, puede afectar a derechos tan fundamentales como la libertad ideológica, la libertad de información, la libertad de expresión o la participación política que son objetivos educativos fundamentales en sociedades democráticas. Por ello, las empresas publicitarias y de medios de comunicación son también responsables de 
buena parte de los procesos informativos, formativos y recreativos en los que están inmersos los ciudadanos; es decir, son copartícipes de la responsabilidad educativa de toda la sociedad. Como señala Rodríguez Neira (2000) en el pasado, en el presente, y así ocurrirá con mayor intensidad en el futuro, habrá instituciones poderosas empeñadas en inculcar determinadas informaciones en beneficio de sus propios intereses, de manera que las personas desprovistas de juicio crítico serán víctimas inapelables de todas las dominaciones.

Un programa educativo en esta dirección podría plantearse cuatro objetivos: 1) examinar la naturaleza de la persuasión en la vida cotidiana, 2) comprender cómo influye en nuestra conducta, 3) cómo podemos protegernos cle la publicidad no deseada y 4) cómo podemos llegar a utilizar la persuasión de manera sensata, para que el diálogo se imponga como forma civilizada de resolver las discrepancias (Pratkanis y Aronson, 1994, 14).

c) Hemos visto cómo la globalización económica, la libertad de mercado y la necesidad de competir reduciendo costos, conducen a una fuerte concentración de empresas en el mundo de los medios de comunicación y de las nuevas tecnologías. Ello creará nuevas formas de exclusión social derivadas de las desigualdades en la capacidad de acceso y utilización de esos poderosos instrumentos de información y difusión de las ideas (Majó, 2000, 77). Por todo ello, los medios de comunicación y las nuevas tecnologías han de ser contemplados en los planes de enseñanza, en su triple dimensión de contenidos, recursos para la enseñanza y medios de expresión y aprendizaje, para evitar que sean instrumentos de manipulación y exclusión social. Su comprensión y dominio los convierten en poderosas herramientas de relación humana, de desarrollo personal y participación social.

Educar en y con los medios de comunicación no tendrá más virtudes ni más defectos que el proyecto global de intervención educativa en el que se inserte. Por ello, si lo que queremos es formar sujetos autónomos y participativos comprometidos con el desarrollo de los derechos humanos en sociedades democráticas, el modelo educativo ha de ser crítico y activo con los medios dentro de un modelo humanizador basado en valores. Si es cierto que los efectos educativos de los medios en el contexto neoliberal actual favorecen más la inhibición que la potenciación de aprendizajes educativos, no es menos cierto que en tanto que instrumentos e incluso como contenidos, permiten ser recontextualizados y apropiados por otro tipo de cultura alejada del consumismo, la banalidad o el hedonismo. Se trataría, por lo tanto, de introducirlos en los contextos educativos para utilizarlos con fines pedagógicos.

d) La educación para el consumo se presenta como otra alternativa para favorecer el desarrollo de una cultura ciudadana, en la demanda de bienes y servicios, que compense el enorme poder del que disponen hoy tanto el sector productivo como el distribuidor. Los objetivos finales de este tipo de educación han de ser dos: capacitar a los sujetos para ser más autónomos en la toma de decisiones y más solidarios en la vida comunitaria. Para el logro de ambos es necesario comprender los 
mecanismos de tipo estructural que condicionan tanto la producción como el consumo. De igual modo, interesan por igual los objetivos de tipo cognitivo, los procedimentales y los actitudinales, tal y como establece la LOGSE. La educación para el consumo es un derecho necesario, junto con otros, para el ejercicio de la ciudadanía en una sociedad democrática. En España, las primeras experiencias en esta materia surgen a finales de los años setenta en distintas comunidades autónomas, promovidas por grupos de renovación pedagógica en colaboración con organismos oficiales y asociaciones. En la actualidad, la educación del consumidor está considerada como eje transversal que debería ser trabajado en las diferentes áreas de conocimiento.

e) Otro de los aspectos en los que ha de incidir la educación para contrarrestar los efectos no deseados de los medios de comunicación es la educación para la democracia. La democracia se debilita cuando la opinión pública está fuertemente mediatizada por unos medios de comunicación poderosos, concentrados en pocas manos, capaces de condicionar, en interés de grupos particulares, las decisiones de quienes han sido elegidos en las urnas para representar a todos los ciudadanos. Si la democracia no hace avanzar la cultura de la participación, corre el riesgo de quedar reducida a una democracia espectadora, pasiva, controlada por unas minorías que controlan los estados de opinión. Por ello, la educación cívica ha de fomentar la participación crítica, la convivencia pacífica, una actitud de defensa de los derechos humanos y una postura abierta a la diversidad. La LOGSE permite un tratamiento escolar de todas estas cuestiones al considerar la educación moral y cívica como uno de los ejes transversales que han de constituir el interés prioritario de todos los profesores cualquiera que sea el área o la materia en la que trabajen.

Hemos expuesto nuestra opinión respecto a las carencias de un modelo de globalización basado sólo en el crecimiento económico y la necesidad de corregirlo mediante un concepto alternativo de globalización que, basado en el principio de dignidad humana, pueda plantearse los problemas sociales a escala mundial. Lo que Adela Cortina (1997) denomina globalización ética exige un nuevo concepto de ciudadanía social que encajaría bien en la propuesta de Colom (2000, 100) de una educación para el desarrollo. Esta educación, que implica desarrollar una conciencia local pero a la vez planetaria, como partes de un mismo proceso, iría dirigida a lograr una visión sistémica y global del hombre y de la naturaleza. Detrás de cada propuesta educativa hay siempre un modelo de sociedad que la inspira. Dado que vivimos en una sociedad global, compleja y cambiante, la escuela no puede contentarse con transmitir conocimientos y habilidades sin contextualizarlos en su dimensión social, cívica y moral. Tampoco los profesores podemos desvincularnos intelectualmente de los problemas cambiantes de nuestro tiempo, que nos obligan a ejercer la enseñanza clarificando los objetivos que pretendemos al educar. Espero que estas reflexiones puedan servir para valorar la influencia educativa de los medios de comunicación en la sociedad actual y para clarificar algunos de los objetivos que nos podrían ayudar a utilizarlos al servicio de un modelo de convivencia global más justo. 


\section{BiBLIOGRAFÍA}

AMIN, S. (1999) El capitalismo en la era de la globalización. Barcelona, Paidós.

ARNANZ, E. y ARDID, M. (1996) La pobreza en el mundo. Madrid, Aguilar.

BISSIO, R. (1998) Nuevas armas para los demócratas, en RAMONET, I. (ed.). Internet, el mundo que llega. Los nuevos caminos de la comunicación. Madrid, Alianza, 121-129.

BOTKIN, J. W. y otros (1979) Aprender, borizonte sin limites. Madrid, Siglo XXI, Santillana.

CARIDE, J. A. y MEIRA, P. A. (1998) Educación ambiental y desarrollo: La sustentabilidad y lo comunitario como alternativas, Revista Pedagogía Social, 2, 7-30.

COLOM, A. J. (1998) El desarrollo sostenible y la educación para el desarrollo, Revista Pedagogía Social, 2, 31-49.

- (2000) Cuestiones curriculares: problemas y perspectivas II, en RODRÍGUEZ NEIRA, T.; PEÑA CALVO, J. V. y HERNÁNDEZ GARCÍA (coords.). Cambio Educativo: presente y futuro. Oviedo, Universidad de Oviedo, 97-108.

CORTINA, A. (1995) La ética de la sociedad civil (2. a edición). Madrid, Anaya.

- (1997) Ciudadanos del mundo. Hacia una teoria de la ciudadanía. Madrid, Alianza.

CUETO, J. (1981) La sociedad de consumo de masas. Barcelona, Salvat.

DÍAZ, B. (1995) Los medios y la hipótesis de la democracia degradada. Málaga, Universidad de Málaga.

DRUCKER, P. F. (1993) La sociedad postcapitalista. Barcelona, Apóstrofe.

ECHEVERRÍA, J. (1994) Telépolis. Barcelona, Destino.

ESCUDERO, J. M. (1995) Tecnología e innovación educativa, Bordón, 47 (2), 161-175.

JORDÁN, J. A. (1995) Concepto y objeto de la educación cívica, Pedagogia Social, 10, 7-18.

LEÓN, J. L. (1996) Los efectos de la publicidad. Barcelona, Ariel.

LIPOVETSKY, G. (1990) El imperio de lo efimero. La moda y su destino en las sociedades modernas. Barcelona, Anagrama.

MAJÓ, J. (2000) Educación, ciencia y tecnología, en RODRÍGUEZ NEIRA, T.; PEÑA CALVO, J. V. y HERNÁNDEZ GARCÍA (coords.). Cambio Educativo: presente y futuro. Oviedo, Universidad de Oviedo, 75-83.

MARTÍNEZ, M.; BUXARRAIS, R. y VERA, J. (1996) Educación y modelos de aprendizaje social, en ESCÁMEZ, J. (coord.). Acción educativa y comunicación social. Valencia, Tirant Lo Blanch, 17-67.

MATTELART, A. (1998) La mundialización de la comunicación. Barcelona, Paidós.

ORTEGA ESTEBAN, J. (1997) Delincuencia juvenil y televisión, Revista de Educación Social, 7, 97-106.

PÉREZ, A. (1998) La cultura escolar en la sociedad neoliberal. Madrid, Morata.

PÉREZ, J. M.; TROPEA, F.; SANAGUSTÍN, P. y COSTA, P. O. (1992) La seducción de la opulencia. Publicidad, moda y consumo. Barcelona, Paidós.

POSTMAN, N. (1994) Tecnópolis. La rendición de la cultura a la tecnología. Barcelona, Galaxia Gutemberg, Círculo de Lectores.

PRATKANIS, A. y ARONSON, E. (1994) La era de la propaganda. Uso y abuso de la persuasión. Barcelona, Paidós.

QUALTER, Terence H. (1994) Publicidad y democracia en la sociedad de masas. Barcelona, Paidós.

RAMONET, I. (1996) Pensamiento único y nuevos amos del mundo, en CHOMSKY, N. y RAMONET, I. Cómo nos venden la moto (2. a edición). Barcelona, Icaria, 55-98.

- (1998) La tiranía de la comunicación. Madrid, Debate. 
INFLUENCIA EDUCATIVA DE LOS MEDIOS DE COMUNICACIÓN SOCIAL EN LA SOCIEDAD NEOLIBERAL

RODRÍGUEZ NEIRA, T. (2000) Cambio tecnológico y educación, en RODRÍGUEZ NEIRA, T.; PEÑA CALVO, J. V. y HERNÁNDEZ GARCÍA (coords.). Cambio Educativo: presente y futuro. Oviedo, Universidad de Oviedo, 1-21.

RUBIO, J. (1996) Educación moral, posmodernidad y democracia. Madrid, Trotta.

SANAGUSTÍN, P. y otros (1991) El sueño consumista. Sevilla, Consejería de Salud de la Junta de Andalucía.

SARRAMONA, J. y otros (1988) Medios de comunicación de masas y educación, en SARRAMONA, J. (ed.). Comunicación y educación. Barcelona, Ceac, 136-157.

SCHILLER, D. (1998) Los mercaderes de la Aldea Global, en RAMONET, I. (ed.). Internet, el mundo que llega. Los nuevos caminos de la comunicación. Madrid, Alianza, 72-85.

TOFFLER, A. (1976) El shock del futuro. Barcelona, Plaza y Janés.

- (1981) La tercera ola (4. ․ ed.). Barcelona, Plaza y Janés.

VERA, J. (1995) La educación y el sistema publicidad/moda, Bordón, 47 (1), 79-85.

- (1997) Cambio social y evaluación pedagógica de las tecnologías, Revista Española de Pedagogia, 207, 363-376.

- (1998) Educación social e impacto educativo de los medios persuasivos: publicidad y propaganda, Revista de Educación, 316, 193-213.

- (1999) La publicidad en Educación Social Especializada, en ORTEGA ESTEBAN, J. (coord.). Pedagogía Social Especializada. Barcelona, Ariel, 123-126. 